\title{
Penerapan Terapi Social Skills Training Pada Klien Isolasi Sosial dengan Pendekatan Teori Dorothy E. Johnson Behavioral System Model di Kelurahan Balumbang Jaya Kecamatan Bogor Barat Kota Bogor
}

\author{
Sutejo ${ }^{\mathrm{a}}$ \\ aJurusan Keperawatan Poltekkes Kemenkes Yogyakarta \\ E-mail:decsuthe@yahoo.com
}

\begin{abstract}
Prevalence of mental disorders has increase significantly each year. The intervention is not only foccus in hospital, but also in community that called community mental health. Heavy mental disorders that often happened is schizophrenia, in wich the client has failed to do social function, failed to cope interpersonal skill problems, have poor social skills, and have deficit cognitif function. This scientific paper is aim to have description about application of social skill training therapy to the client with social isolated through the ability to interacting to others utilizing Behavioral System Model approach. The amount of clients is 13 of 38 mental disorders client. The result is client able to show improvement in verbal and non verbal communication and also able to interacting to others around. The recommendation of this scientific paper is nurse have competency to apply social skills training to client with social isolated and the importance to have mental health nurse specialist in community area.
\end{abstract}

Key words: social skills training therapy, social isolated, behavioral system model

\begin{abstract}
Abstrak: Prevalensi gangguan jiwa setiap tahun mengalami peningkatan cukup signifikan. Program intervensi yang dapat dilakukan tidak hanya berfokus di rumah sakit namun juga dilingkungan masyarakat dalam bentuk kesehatan jiwa masyarakat. Karya ilmiah akhir ini bertujuan menggambarkan penerapan terapi social skills training pada klien isolasi sosial terhadap kemampuan dalam berinteraksi dengan orang lain melalui pendekatan teori Behavioral System Model. Jumlah klien yang dikelola sebanyak 13 klien dari 38 klien gangguan jiwa. Hasil yang diperoleh yaitu klien mampu menunjukkan peningkatan keterampilan berkomunikasi secara verbal maupun non verbal serta mampu melakukan interaksi dengan orang lain yang berada disekitarnya. Rekomendasi hasil karya ilmiah ini adalah perawat memiliki kompetensi pelaksanaan terapi social skills training pada klien isolasi sosial dan perlunya perawat spesialis jiwa di area komunitas.
\end{abstract}

Kata kunci: terapi social skills training, isolasi sosial, behavioral system model

PENDAHULUAN

Organisasi Kesehatan Dunia atau WHO (2003) mendefinisikan kesehatan sebagai keadaan sehat fisik, mental dan sosial bukan semata - mata keadaan tanpa penyakit atau kelemahan. Faktor yang mempengaruhi kesehatan jiwa seseorang dapat dikategorikan sebagai faktor individual, interpersonal dan sosial budaya (Seaward, 1997 dalam Videbeck, 2006).

Prevalensi terjadinya gangguan jiwa tahun demi tahun selalu mengalami peningkatan yang cukup signifikan.
Menurut data WHO (2003) menjelaskan bahwa pada tahun 2001 menunjukkan paling tidak satu dari empat orang di dunia atau sekitar 450 juta orang mengalami gangguan jiwa. Sedangkan di Indonesia sendiri berdasarkan Riset Kesehatan Dasar tahun 2007 (Depkes, 2008) menujukkan angka kejadian gangguan jiwa berat sebesar 4,6\% Tingginya angka gangguan jiwa tersebut mengindikasikan bahwa individu yang mengalami gangguan jiwa apabila tidak ditangani dengan baik dapat berpengaruh terhadap kualitas hidupnya sehingga 
berdampak kepada keluarga maupun masyarakat.

Data gangguan jiwa tersebut merupakan jumlah yang sangat besar sehingga memerlukan perhatian serius berupa program intervensi yang implementasinya bukan hanya ditatanan rumah sakit namun juga di lingkungan masyarakat (community - based psychiatric service) dalam bentuk kesehatan jiwa masyarakat. Menurut Videbeck (2006) bahwa pelayanan kesehatan jiwa berbasis masyarakat dikembangkan menjadi suatu kebutuhan yang dapat menurunkan biaya perawatan dan memberikan kenyamanan karena klien tetap dapat tinggal dan berhubungan dengan keluarga.

Kelompok Keilmuan Keperawatan Jiwa FIK UI melakukan pengembangan area praktik bagi mahasiswa melalui pembentukan Desa/RW Siaga Sehat Jiwa yaitu di wilayah Bogor. Berdasarkan proses koordinasi dengan Dinas Kesehatan Kota Bogor maka ditetapkanlah Kelurahan Sindang Barang dan Kelurahan Bubulak Kecamatan Bogor Barat sebagai wilayah di Kota Bogor yang perlu untuk dilakukan suatu program pemenuhan kebutuhan kesehatan jiwa. Menindaklanjuti keberhasilan pembentukan RW Siaga Sehat Jiwa di kedua wilayah tersebut, maka disepakati bersama bahwa Kelurahan Balumbang Jaya menjadi wilayah ketiga untuk dibentuk RW Siaga Sehat Jiwa.

Dari studi awal yang dilakukan, maka diperoleh data bahwa masyarakat maupun kader sangat antusias dengan kegiatan RW Siaga Sehat Jiwa dan menginginkan adanya upaya tindak lanjut. Salah satu kegiatan dalam mensukseskan RW Siaga Sehat Jiwa yaitu pelatihan Kader Kesehatan Jiwa, pembentukan struktur organisasi KKJ dan deteksi dini dimana yang mengalami gangguan jiwa sebanyak 38 orang. Apabila data gangguan jiwa tersebut dihitung maka dapat disimpulkan bahwa prevalensi gangguan jiwa di Kelurahan Balumbang Jaya sebesar $0,38 \%$ atau lebih besar daripada prevalensi di Jawa Barat yakni
$0,22 \%$.

Klien skizofrenia sering mengalami kegagalan dalam menjalankan fungsi sosial, menghadapi masalah yang berhubungan dengan keterampilan interpersonal, memiliki keterampilan sosial yang buruk dan mengalami defisit fungsi kognitif. Isolasi sosial sebagai salah satu respon perilaku negatif yang muncul pada klien skizofrenia ditandai dengan individu mengalami penurunan dan bahkan sama sekali tidak mampu berinteraksi dengan orang lain disekitarnya (Keliat dkk, 2006).

Kondisi klien isolasi sosial yang tidak mengganggu dan tidak merusak lingkungan, mengakibatkan pemberian asuhan keperawatan kepada klien terabaikan. Salah satu terapi spesialis keperawatan jiwa pada klien isolasi sosial adalah terapi social skills training. Penelitian yang telah dilakukan oleh Renidayati (2008) menunjukkan bahwa menjadi terapi spesialis keperawatan jiwa khususnya pada klien isolasi sosial di RSJ HB Saanin Padang menunjukkan hasil bahwa kemampuan kognitif dan perilaku klien lebih tinggi pada kelompok intervensi.

Masalah keperawatan isolasi sosial yang dialami oleh klien gangguan jiwa selama praktik pengembangan model pelayanan kesehatan jiwa di Kelurahan Balumbang Jaya sejak tanggal 19 Oktober 2009 sampai dengan 09 April 2010 yakni 18 klien. Diagnosa keperawatan isolasi sosial menduduki peringkat pertama dari asuhan keperawatan spesialis jiwa. Sedangkan dignosa keperawatan lainnya yang ditemukan adalah halusinasi, resiko perilaku kekerasan, harga diri rendah, defisit perawatan diri dan penatalaksanan regiment terapeutik tidak efektif.

Tindakan keperawatan yang diberikan adalah terapi generalis untuk masing masing diagnosa serta terapi spesialis spesialis untuk individu (terapi kognitif, terapi perilaku, terapi perilaku kognitif, terapi social skills training, assertiveness training). Terapi kelompok (terapi suportif, 
self help group) dan keluarga (psikoedukasi keluarga).

Penatalaksanaan masalah isolasi sosial di Kelurahan Balumbang Jaya menggunakan teori yang dikembangkan oleh Dorothy E. Johnson yakni Behavioral System Model. Model ini ditujukan agar keperawatan lebih mengembangkan fungsi-fungsi perilaku manusia yang secara efektif dan efisien. Jonhson dalam hal ini juga menjelaskan bahwa perilaku manusia adalah sistem yang akan dipengaruhi oleh subsistemnya yaitu lingkungan, dan masalah kesehatan. Subsistem lain yang juga akan memberikan pengaruh terhadap perilaku manusia yaitu tujuan dari intervensi yang dilakukan oleh perawat dalam rangka memperoleh kembali kestabilannya.

Terapi social skills training merupakan suatu teknik modifikasi perilaku yang telah banyak dilakukan dan diteliti tingkat keberhasilannya. Melalui penerapan terapi tersebut, klien memperoleh proses pembelajaran perilaku dalam meningkatkan kemampuannya dalam berinteraksi dengan orang lain agar dapat diterima dan dihargai secara sosial. Hal inilah yang mendasari penulis untuk memilih model konsep Johnson's Behavioral System Model sebagai landasan untuk pemberian terapi social skills taining pada pasien klien isolasi sosial di Kelurahan Balumbang Jaya Kecamatan Bogor Barat Kota Bogor.

\section{METODE}

Tinjauan teori isolasi sosial, terapi social skills training, teori dorothy e. Johnson behavioral system model

Isolasi sosial adalah suatu pengalaman menyendiri seseorang dan perasaan segan terhadap orang lain sebagai sesuatu yang negatif dan keadaan yang mengancam. Berbagai faktor bisa menimbulkan isolasi sosial, belum ada suatu kesimpulan spesifik tentang penyebab pasti terjadinya gangguan hubungan interpersonal penyebab isolasi sosial. Hal ini disebabkan proses terjadinya isolasi sosial merupakan kombinasi dari berbagai faktor. Proses terjadinya isolasi sosial dilihat dengan pendekatan holistik.

Tanda dan gejala isolasi sosial menurut Keliat, dkk (2006); Stuart dan Laraia (2005) meliputi; fisik, kognitif, perilaku dan afektif. Tanda dan gejala fisik, merupakan manifestasi respon fisiologis tubuh terhadap masalah isolasi sosial ditandai dengan kurang energi, lemah, agitasi, penurunan libido, insomia atau hipersomia, penurunan dan peningkatan nafsu makan. Klien kurang tekun bekerja dan sekolah, kesulitan melaksanakan tugas yang komplek, lebih banyak diam, tidak mau kontak mata, berbaring dengan posisi fetus. Kondisi ini akan menunjukkan perilaku yang maladaptif pada klien.

Intervensi keperawatan spesialis jiwa pada klien dengan isolasi sosial dapat dilakukan dengan mengacu pada 4 (empat) terapi yaitu terapi individu, keluarga, kelompok dan komunitas. Menurut Kneisl, dkk (2004); Stuart dan Laraia (2005), terapi individu yang dapat diberikan pada klien isolasi sosial adalah terapi kognitif, cognitive behaviour therapy dan social skills training. Terapi pada kelompok klien juga perlu dilakukan seperti terapi aktivitas kelompok sosialisasi, terapi suportif, logoterapi dan psikoedukasi keluarga.

Tujuan social skills training adalah untuk menurunkan kecemasan meningkatkan kontrol diri pada klen dengan fobia sosial, meningkatkan kemampuan klien dalam aktifitas bersama, bekerja dan meningkatkan kemampuan sosial klien skizofrenia (Van Dam Baggen \& Kraaimaat, 2000 dalam Kneisl dkk, 2004).

Social skills training sebagai salah satu teknik modifikasi perilaku telah banyak dilakukan dan diteliti pula tingkat keberhasilannya. Efektif digunakan untuk meningkatkan kemampuan seseorang untuk berinteraksi, meningkatkan harga diri, meningkatkan kineja dan menurunkan tingkat kecemasan. Terapi ini dapat diberikan pada klien; skizofrenia, klien depresi, ansietas dan fobia sosial yang 
mengalami masalah isolasi sosial, harga diri rendah, perilaku kekerasan dan cemas.

Terapi social skills training merupakan kompetensi perawat spesialis jiwa. Renidayati (2008) mengembangkan modul social skills training pada klien isolasi sosial dengan mengacu pada 4 (empat) tahapan social skills training yang dikemukakan Stuart dan Laraia (2005) yakni melatih kemampuan klien berkomunikasi, menjalin persahabatan dan menghadapi situasi sulit, dengan menggunakan metode modelling, role play, feedback dan transfer training.

Fokus penekanan pada model Johnson menurut Leddy dan Pepper (1993, dalam Tomey \& Aligood, 2006) adalah, pada individu sebagai sistem perilaku. Sistem tersebut teridentifikasi oleh tindakan dan perilaku yang teratur dan terkontrol oleh faktor - faktor biologis, psikologis, dan sosiologis. Sistem terdiri dari ketujuh hasil interaksi subsistem yang mengakibatkan fungsi spesifik untuk semua sistem secara menyeluruh.

Behavioral Sistem Model milik Johnson memiliki skematik yang jelas untuk menggambarkan interaksi antara subsistem yang ada dalam sistem manusia, seperti yang dijelaskan pada gambar dibawah ini :

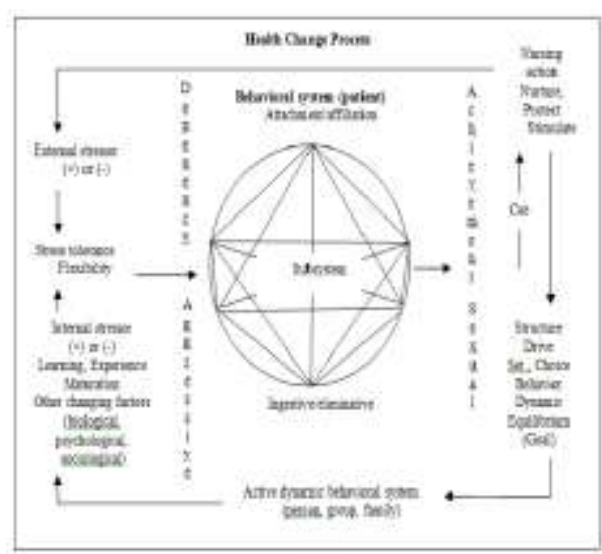

Gambar 2.1 Johnson's Behavioral System Model

Aplikasi dari setiap model untuk praktek keperawatan membutuhkan tiga kondisi: model praktik kesesuaian dengan persyaratan, maka pembangunan yang komprehensif dalam kaitannya dengan praktik mempunyai persyaratan, dan kekhususan dalam kaitannya dengan praktik keperawatan.

\section{Pelaksanaan terapi social skills training pada klien isolasi sosial}

Jumlah klien gangguan jiwa yang ada di Kelurahan Balumbang Jaya sebanyak 38 orang dan yang mengalami masalah keperawatan isolasi sosial yaitu 18 orang $(47,37 \%)$. Klien dengan isolasi sosial seluruhnya sudah diberikan terapi generalis namun yang telah diberikan terapi spesialis social skills training hanya berjumlah 13 orang. Hal tersebut dikarenakan kondisi klien yang tidak memungkinkan untuk dilakukan terapi social skills training yakni pada klien dengan tuna grahita, tuna netra, tuna rungu dan tuna wicara.

Masalah isolasi sosial pada klien gangguan jiwa di Kelurahan Balumbang Jaya merupakan diagnosa keperawatan terbanyak kedua setelah harga diri rendah. Diagnosa medis sudah dapat ditegakkan pada seluruh klien isolasi sosial hal tersebut merupakan hasil kolaborasi antara perawat CMHN dengan dokter Puskesmas yang bertanggung jawab langsung terhadap program kesehatan jiwa di wilayah Puskesmas Sindang Barang.

Asuhan keperawatan pada klien dengan isolasi sosial di Kelurahan Balumbang Jaya dilakukan berdasarkan penatalaksanaan keperawatan dan medis. Pengukuran hasil kemampuan klien dengan masalah isolasi sosial dinilai dengan cara membandingkan hasil pengkajian awal dengan kondisi setelah diberikan terapi spesialis keperawatan jiwa. Kendala yang dihadapi meliputi pelaksanaan terapi, keterlibatan petugas kesehatan dan lingkungan perawatan. Tindak lanjut yang akan dilakukan berfokus pada klien dan keluarga, lingkungan perawatan dan institusi pendidikan.

\section{HASIL DAN PEMBAHASAN}


Klien dengan masalah isolasi sosial yang diberikan terapi social skills training $76,92 \%$ berusia antara antara $25-50$ tahun. Menurut Erikson (1963, dalam Potter \& Perry, 2005 ) bahwa usia tersebut tergolong kedalam usia dewasa. Tahap usia dewasa merupakan masa produktif dimana klien memiliki tuntutan aktualisasi diri baik dari diri sendiri, keluarga maupun lingkungan. Jenis kelamin yang teridentifikasi dari 13 klien dengan isolasi sosial menunjukkan bahwa mayoritas $(92,31 \%)$ adalah laki - laki. Hal ini sesuai dengan penelitian yang dilakukan oleh Renidayati (2008) bahwa isolasi sosial banyak dialami oleh laki - laki dibanding perempuan.

Klien dengan isolasi sosial sebagian besar memiliki tingkat pendidikan rendah yaitu SD. Menurut Potter dan Perry (2005) bahwa pendidikan lebih tinggi akan memberikan pengetahuan yang lebih besar sehingga menghasilkan kebiasaan mempertahankan kesehatan yang lebih baik. Karakteristik pekerjaan pada klien isolasi sosial mayoritas tidak bekerja. Hal tersebut sesuai dengan pendapat Townsend (2005) yang menjelaskan bahwa tingkat sosial ekonomi rendah merupakan salah satu faktor sosial yang menyebabkan tingginya angka gangguan jiwa termasuk skizofrenia.

Klien isolasi sosial yang dikelola selama kegiatan residensi sebagian besar belum menikah. dengan isolasi sosial sebagian besar total care. Pada umumnya klien sudah memiliki riwayat gangguan jiwa yang sudah lama, putus obat dan kurang pengetahuan keluarga dalam hal perawatan klien dirumah.

Menurut Stuart dan Laraia (2005) faktor predisposisi adalah faktor risiko yang mempengaruhi jenis dan jumlah sumber yang dapat dibangkitkan oleh individu yang mengalami stress. Menurut Townsend (2005) bahwa faktor biologis akan terkait dengan adanya neuropatologi dan ketidakseimbangan dari neurotransmiternya. Menurut Stuart dan Laraia (2005) bahwa faktor psikologis terdiri dari konsep diri, intelektualitas, kepribadian, moralitas, pengalaman masa lalu, koping dan keterampilan komunikasi secara verbal. Menurut Townsend (2005) menjelaskan bahwa faktor sosial budaya dikaitkan dengan terjadinya isolasi sosial meliputi : umur, jenis kelamin, pendidikan, pekerjaan dan keyakinan.

Hasil pengkajian faktor presipitasi pada klien dengan isolasi sosial terdiri dari faktor biologis yaitu putus obat. Alasan yang ditemukan pada klien dengan riwayat putus obat adalah perasaan bosan, merasa sudah sembuh atau keluarga khawatir bahwa kondisi klien akan ketergantungan kepada obat.

Kurangnya informasi keluarga yang adekuat dari fasilitas kesehatan tentang manfaat obat berdampak pada angka kekambuhan sehingga memperburuk keadaan klien. Hal tersebut sesuai dengan pendapat Shives (2005) yang menjelaskan bahwa pasien yang sudah pernah kambuh memiliki prognosis yang kurang baik dibandingkan pasien baru.

Penilaian stresor yang ditemukan berdasarkan hasil pengkajian pada klien isolasi sosial dimanifestasikan dalam bentuk respon kognitif, respon afektif, respon fisiologis, respon perilaku dan respon sosial. Sumber koping yang teridentifikasi berdasarkan hasil pengkajian pada klien isolasi sosial terdiri dari empat sumber koping yaitu kemampuan personal, dukungan sosial, ketersediaan aset dan keyakinan positif. Menurut Stuart dan Laraia (2005) bahwa kemampuan klien yang harus dimiliki oleh individu meliputi tiga hal penting yaitu kemampuan dalam mengenal atau mengidentifikasi masalah, menentukan masalah serta menyelesaikan masalah.

Hubungan karakteristik klien isolasi sosial dengan hasil manajemen kasus menunjukkan hasil tidak ada perbedaan. Pelaksanaan manajemen kasus pada klien dengan isolasi sosial terdiri dari dari pengkajian, penetapan diagnosa keperawatan, merencanakan tindakan keperawatan, melaksanakan tindakan 
keperawatan dan melakukan evaluasi terhadap tindakan yang dilakukan.

Menurut teori Johnson bahwa kien mempunyai sesuatu yang terintegrasi, sistematik, terpola, memiliki tujuan, dan cara untuk memprediksi sesuatu. Perilaku menjadi bagian, orientasi, sistem, pola dan prediksi dari tujuan klien. Hal tersebut menjadi dasar untuk melaksanakan terapi social skills training pada klien isolasi sosial.

Terapi social skills training merupakan terapi spesialis keperawatan jiwa yang merupakan sebuah proses pembelajaran bagi klien untuk meningkatkan kemampuannya dalam berinteraksi dengan orang lain sehingga dapat diterima dan dihargai secara sosial. Pemberian terapi social skills training berdasarkan pendekatan teori Johnson's Behavioral System Model yang ditujukan agar keperawatan lebih mengembangkan fungsi - fungsi perilaku manusia yang secara efektif dan efisien.

Intervensi keperawatan khususnya pada klien dengan isolasi sosial dilakukan secara komprehensif dan holistik serta terintegrasi kedalam sistem keluarga sebagai sumber pendukung bagi klien. Menurut Townsend (2005) hubungan dalam keluarga merupakan faktor utama yang mempengaruhi perkembangan terhadap adanya penyakit atau gangguan yang dialami oleh seseorang.

Terapi social skills training secara nyata memberikan dampak yang sangat berarti pada klien isolasi sosial yaitu menunjukkan peningkatan kemampuan yang signifikan dalam berinteraksi dengan orang lain baik didalam keluarga maupun di masyarakat. Klien yang sudah mampu bersosialisasi dapat memperluas pergaulan dan memiliki banyak teman sehingga membuka wawasan terhadap lingkungan sekitar. Melalui pemberian terapi social skills training ternyata memberikan dampak positif terhadap perubahan perilaku klien khususnya kemampuan berinteraksi terutama dengan anggota keluarga yang lain.

Menurut Tomey dan Alligood (2006) menjelaskan bahwa Johnson memandang kesehatan menjadi suatu nilai yang diinginkan oleh petugas kesehatan yang berfokus pada individu dan bukan pada penyakit. Kesehatan direfleksikan sebagai sistem perilaku yang terorganisir, berinteraksi, dan saling ketergantungan dari setiap subsistemnya.

Klien isolasi sosial yang diberikan terapi social skills training menunjukkan adanya ketersediaan sumber pendukung baik internal dan eksternal. Sumber internal berasal dari potensi diri, sedangkan sumber eksternal berasal keluarga, KKJ serta petugas kesehatan. Berdasarkan temuan data pada klien dengan isolasi sosial memiliki kecenderungan kurang kurang mampu memanfaatkan potensi yang ada pada dirinya maupun sumber yang berasal dari luar.

\section{KESIMPULAN DAN SARAN}

Karakteristik klien dengan masalah isolasi sosial di Kelurahan Balumbang Jaya mayoritas berusia dewasa, jenis kelamin sebagian besar laki - laki, banyak yang tidak memiliki pekerjaan, pendidikan rata rata rendah (SD), hampir seluruhnya belum menikah dan tingkat kemandirian sebagian besar total care.

Faktor predisposisi penyebab isolasi sosial yang paling banyak ditemukan adalah pada aspek sosial budaya yaitu kepribadian tertutup dan memiliki riwayat kehilangan. Faktor presipitasi yang paling banyak ditemukan pada klien isolasi sosial yaitu pada aspek sosial budaya yaitu tidak memiliki pekerjaan dengan jumlah stresor lebih dari dua stresor dalamnya rata - rata lima tahun.

Diagnosa medis yang paling banyak ditemukan adalah skizofrenia paranoid, sedangkan diagnosa keperawatan pada klien rata - rata memiliki lebih dari satu diagnosa. Terapi spesialis keperawatan jiwa yang diberikan terdiri dari terapi social skills training, terapi perilaku, terapi 
kognitif, terapi perilaku kognitif, terapi suportif, terapi assertiveness training, self help group dan psikoedukasi keluarga.

Klien dengan isolasi sosial yang hanya mendapatkan terapi social skills training sebanyak 6 orang. Hasil yang diperoleh yaitu klien mampu menunjukkan peningkatan keterampilan berkomunikasi baik secara verbal maupun non verbal serta mampu melakukan interaksi dengan orang lain yang berada disekitarnya.

Semua karakteristik klien isolasi sosial memiliki hubungan terhadap hasil pelaksanaan manajemen kasus spesialis. Efektifitas pelaksanaan terapi social skills training pada klien isolasi sosial dengan pendekatan Behavioral System Johnson ditujukan agar keperawatan lebih mengembangkan fungsi - fungsi perilaku manusia secara optimal. Hal ini menegaskan bahwa perilaku manusia adalah sistem yang dipengaruhi oleh subsistemnya yaitu lingkungan dan masalah kesehatan. Penerapan terapi social skills training memberikan dampak yang efektif dalam mengembangkan perilaku positif khususnya dalam hal kemampuan berinterkasi dengan orang lain sesuai dengan subsistem perilaku yang dimiliki klien.

Hal yang disarankan kepada pihak pihak terkait adalah berupaya meningkatkan pelayanan kesehatan jiwa khususnya di area komunitas. Keterlibatan pelayanan kesehatan (Dinas Kesehatan Kota, Puskesmas, Kelurahan), institusi pendidikan, organisasi profesi, klien, keluarga, kader kesehatan jiwa dan masyarakat sangat diharapkan guna mencapai derajat kesehatan jiwa secara optimal.

\section{DAFTAR PUSTAKA}

Departemen Kesehatan Republik Indonesia. (2008). Riset kesehatan dasar 2007. http://www.litbang.depkes.go.id/Lapora nRKD/IndonesiaNasional.pdf, diperoleh tanggal 22 Februari 2009.

Keliat, B.A., dkk. (2006). Modul IC CMHN: Manajemen kasus gangguan jiwa dalam keperawatan kesehatan jiwa komunitas. Jakarta: WHO \& FIK UI.

Kneisl, C.R., dkk. (2004). Contemporary psychiatric mental health nursing. New Jersey: Pearson Prentice Hall.

Potter, P.A \& Perry, A.G. (2005). Buku ajar fundamental keperawatan: Konsep, proses \& praktik. Voume 2. Edisi 4. Aih bahasa : Renata Komalasari, dkk. Jakarta: EGC.

Ramdhani, N. (2002). Pelatihan keterampilan sosial untuk terapi kesulitan bergaul. http://www.libugm.ac.id/data/pubdata/ ketsos.pdf. diperoleh tanggal 16 April 2010.

Renidayati. (2008). Pengaruh social skill training pada klien isolasi sosial di Rumah Sakit Jiwa Prof HB Saanin Padang. Tesis. FIK UI. Tidak dipublikasikan

Shives, L.R. (2005). Basic concept of psychiatric mental health nursing. $\left(6^{\text {th }}\right.$ ed). Philadelphia: Lippincott Williams \& Wilkins.

Stuart, G.W \& Laraia, M.T. (2005). Principles and practice of psychiatric nursing. ( ${ }^{\text {th }}$ ed). St. Louis: Mosby Years Book Inc.

Tomey, A.M \& Alligood, M.R. (2006). Nursing theorists and their work. $\left(6^{\text {th }}\right.$ ed). St. Louis: Mosby Years Book Inc.

Townsend, M. C. (2005). Essentials of psychiatric mental health nursing. $\left(3^{\text {th }}\right.$ ed.). Philadelphia: F.A. Davis Company.

Videbeck, S.L. (2006). Psychiatric mental health nursing. $\left(3^{\text {rd }} \mathrm{ed}\right)$. Philadelphia: Lippincott Williams \& Wilkins.

WHO. (2003). Investing in mental health. http://www.who.int/mental_health/en/in vesting_in_mnh_final.pdf. diperoleh tanggal 7 Juni 2010. 